\title{
Social Impact Analysis of Products under a Holistic Approach: A Case Study in the Meat Product Supply Chain
}

\author{
Juan Aranda ${ }^{1}$, David Zambrana-Vásquez ${ }^{2, *}$, Felipe Del-Busto ${ }^{1}$ and Fernando Círez ${ }^{1}$ (I) \\ 1 Circular Economy Group, Fundación CIRCE, 50018 Zaragoza, Spain; jaaranda@fcirce.es (J.A.); \\ dfbusto@fcirce.es (F.D.-B.); fcirez@fcirce.es (F.C.) \\ 2 Instituto Universitario de Investigación Mixto CIRCE, Universidad de Zaragoza, 50018 Zaragoza, Spain \\ * Correspondence: dazambrana@fcirce.es; Tel.: +34-976-976-859
}

Citation: Aranda, J.;

Zambrana-Vásquez, D.; Del-Busto, F.;

Círez, F. Social Impact Analysis of

Products under a Holistic Approach:

A Case Study in the Meat Product

Supply Chain. Sustainability 2021, 13,

12163. https://doi.org/10.3390/

su132112163

Academic Editors: Daizhong Su,

Wenjie Peng, You Wu and Hua Huang

Received: 17 September 2021

Accepted: 1 November 2021

Published: 4 November 2021

Publisher's Note: MDPI stays neutral with regard to jurisdictional claims in published maps and institutional affiliations.

Copyright: (C) 2021 by the authors. Licensee MDPI, Basel, Switzerland. This article is an open access article distributed under the terms and conditions of the Creative Commons Attribution (CC BY) license (https:// creativecommons.org/licenses/by/ $4.0 /)$.

\begin{abstract}
Social impact assessment of products can be approached through different methodologies that need to be adapted to the particularities and features of the studied subject. Thus, the Social Life Cycle Assessment methodology can be used to assess different innovative practices of product manufacturing, under a circular economy approach, by identifying potential positive as well as negative impacts along products' life cycle. This paper presents the results of the Social Life Cycle Impact Assessment of a reference product from the Spanish meat industry using existing and new innovative methods of social impact analysis. Worker discrimination, health and safety for workers, consumers and local community were identified as the social aspects with relevant significance into the business or for the influence on customer's perception of the products studied. Therefore, results can represent a reference scenario for the future assessment of innovative solutions in the Spanish meet sector. Despite the scarce use of Social Life Cycle Impact Assessment, this case study is a good example of how this innovative kind of assessment can be helpful for companies to identify their weak and strong social performance areas and design strategies to improve in Social Responsibility Management.
\end{abstract}

Keywords: social life cycle assessment; circular economy; social impact assessment; sustainability; meat supply chain

\section{Introduction}

Circular economy is mainly based on holistic approaches, involving complete value chains and assessing the effect that any change has on any of its links (i.e., stakeholders). To this end, technical developments are commonly considered but three other perspectives should be considered, environmental, economic, and social impacts [1], in other words, applying Life Cycle Sustainability Assessment. Nowadays, Environmental Life Cycle Assessment (LCA) is a well-introduced tool able to consider environmental impacts from raw materials extraction, transportation, manufacturing processes, use of products, and end-of-life stages. However, this methodology is expandable based on ISO 14040:2006 [2] and 14044:2006 [3] to the other pillars: Economic aspects (Life Cycle Cost Assessment, LCCA) and social impacts (Social Life Cycle Assessment, S-LCA). S-LCA, as based on previous ISO standards, is a tool able to consider different stakeholders and stages along value chains and life of a product, but it is not as spread as environmental LCA so different definitions and methodologies can be found in literature [4-6] mainly based on the subjects that will be assessed [7].

The application of the previous concepts in products as food is a worldwide priority issue. As a proof, Farm to Fork strategies have been included in the large funding R\&D called The European Green Deal [8]. According to Eurobarometer results [9], one of the priorities for European consumers is to be sure that food products are healthy, environmental, social and ethical, and less processed. In this framework and report, the meat sector is one of the worrying fields, mainly focused on antibiotic/hormone residues and environmental/social 
aspects. To this end, the European Commission's main worries about meat is to develop new production pathways that are more sustainable, not only carbon-efficient but also social and safe, based on circular solutions.

The meat sector keeps growing, as regards the last two years, with just small reductions in beef and poultry ( $+26 \%$ for pigs, $+8.6 \%$ lambs, $-1 \%$ poultry, $-1.3 \%$ beef) [10], and is well-studied in terms of Life Cycle Assessment (i.e., [11,12]), but there is not so much development of Social LCA application to food or meat. Some previous literature in this field (agri-food or meat sector) can be found for Irish dairy farms [13] and Canadian dairy farms [14], cheese production in New Zealand [15], conventional pork production compared to organic in Sweden [16], and slaughter meat factories [17]. Among the previous works, one of the main conclusions is that there is not only one methodology to be applied when social sustainability is assessed. Several definitions can be approached through different methodologies [5]. Florman [18] listed general and specific social impact assessment methodologies launched since 1997, as for example, Social Return on Investment (SROI) and Social Value Metrics. More specifically, Rafiaani [5] compared, within bio-based economy, the Social Impact Assessment (SIA), Socio-Economic Impact Assessment (SEIA), and Social Life Cycle Assessment (S-LCA). SIA and SEIA share basically the same approach whereas their main difference is the inclusion of the economic dimension for the latter. As ex-ante evaluation frameworks, usually part of an Environmental Impact Assessment (EIA), their scope is limited to examining the expected consequences from planed interventions, such as new programs or policies, on local communities mainly during the implementation [19]. In contrast, S-LCA is a procedure focused on all the life cycle stages of products and processes, which assesses social and socio-economic features of products, as well as potential positive and negative impacts [20] for local communities, but also for other target groups, such as workers and supply value chain actors. It must be highlighted that existing social impact methodologies at the product level foster flexibility due to relative immaturity and specific background requirements [21]. However, the use of assessment categories as paid work, health and safety, gender and human rights for the design and evaluation of products through S-LCA seems to be a correct approach for the generation of products that generate positive social benefits [22].

The usage of S-LCA for product assessment in industry is scarce, very recent, and comes completing the more matured environmental and cost life cycle assessments [23]. A literature review shows that the application of S-LCA under a Circular Economy approach is lacking application in referring to suppliers' selection or creating indicators to measure sustainability. In the case of the meat industry, some analyses cover just the farming phase (calf farming in Mexico) [24]. The closest to our case is a study about the Swedish pork production sector that was published in 2020, focusing on the analysis of differences between organic and conventional production at a sectoral level [16].

This paper presents the results of the S-LCA applied to a reference product from the Spanish meat supply chain sector using existing and new innovative methods of social impact analysis. The purpose of the analysis is to prove the versatility and utility of a S-LCA to help the company quantify and understand their social performance from a holistic point of view in different social indicators assessed from a life cycle perspective. A comparative analysis with the average national meat sector in Spain is performed to enable the company to identify the strong and weak areas within their competitive area. The selected product is $1 \mathrm{~kg}$ of reference pork loin product from ALIA company. These results represent a reference scenario for the future assessment of innovation solutions that will be developed in the CIRC4LIFE project. CIRC4Life project (a circular economy approach for lifecycles of products and services, funded by the European Union under the H2020 Innovation Framework Programme), is an R\&D project dedicated to create Circular Economy Business Models focused on three different aspects of circular economy: co-creation related to manufacturers, sustainable consumption related to end-users, and collaborative reuse and recycling related to waste managers, end-users, and local industries. One of the tools involved in SLCA is the eco-account scheme based on eco-points and eco- 
credits methodology developed in this project. Therefore, they may be used in calculation of the eco-points (based on LCA, including SLCA figures), and subsequent utilisation for eco-credits and eco-accounting $[25,26]$.

\section{Materials and Methods}

\subsection{Case Study}

The product under analysis is a curated pork loin. It is presented in $900 \mathrm{~g}$ pieces and produced by the Spanish company S.A.T. ALIA. This company is an agri-food cooperative with 245 workers dealing with animal food manufacturing, animal breeding, and pork meat products, located in Lorca (Spain). The company encircles vertically all the activities and processes needed to fully produce ready-to-eat pork meats starting with animal feed products, followed by pork breeding and slaughtering, and finishing with packaging and distribution.

\subsubsection{Scope and Functional Unit}

One kilogram of pork loin meat and the associated packaging film delivered to the end user purchasing spots is selected as the functional unit. The reason to take $1 \mathrm{~kg}$ and not a package of $900 \mathrm{~g}$ is because this is a more standard quantity, which is easier to compare with other products from the company or other competitors and make it coherent with parallel analysis in the environmental and economic domains. The company measures the annual output in $\mathrm{kg}$ and not in number of package units. The packaged amount is an arbitrary quantity that may change next year, thus, hindering any possible comparative analysis. The scope of the analysis comprises the full elaboration process starting from the animal feed manufacturing, the piglet breeding, the slaughtering and the pork loin manufacturing, and packaging. The consumption step requires cooling energy for storage and is out of the scope.

\subsubsection{Life Cycle Inventory}

The Life Cycle Inventory at each manufacturing stage comprises inputs for water, energy, labour, transport, packaging, and other costs. All inputs are given in monetary units converted into 2011's $\$$ and aggregated per manufacturing phase. The reason to use this unit in the inventory is because the "PSILCA database" [27] version used in the analysis is set in this unit. The 2011's US dollar to Euro exchange rate is taken to convert today's costs in euros into 2011's costs in dollars. The exchange rate at 31 December 2011 was 0.75 euros per dollar. We assume similar levels of currency devaluation in the time period. The model of activities is made up by four main impact contributors that include:

- Agricultural products used for animal feed manufacturing, all coming from nearby suppliers at the regional and national levels. The input of the process in economic terms is $0.69 \$$ of agricultural raw materials per $\mathrm{kg}$ of pork meat. This process is external and provided by external ALIA suppliers.

- Animal food manufacturing. This process is fully run by ALIA and the input is $3.69 \mathrm{~kg}$ of agricultural raw material per $\mathrm{kg}$ of animal food or $0.69 \$$ of raw materials per functional unit, plus a number of other inputs like water, energy, labour, transport, packaging, and other costs, totalling $0.94 \$$ per $\mathrm{kg}$ of pork meat.

- Farming and breeding. The input of this process is $3.06 \mathrm{~kg}$ of animal food per $\mathrm{kg}$ of alive animal. Per functional unit, we input $0.94 \$$ of animal food and $0.85 \$$ of energy, labour, water, medicines, transport, and other costs. The process is entirely done at ALIA's premises.

- Pork meat product manufacturing. Including slaughtering, product manufacturing, and distribution. It needs $1.24 \mathrm{~kg}$ of alive animal per $\mathrm{kg}$ of meat. The input is $1.8 \$$ of alive meat per $\mathrm{kg}$ of produced meat. Other inputs at slaughtering account for $0.75 \$$ per $\mathrm{kg}$ of meat. Pork loin manufacturing involves the use of $1.4 \mathrm{~kg}$ of pork meat, pork loin quality, per $\mathrm{kg}$ of loin product. Inputs at manufacturing and distribution amount to $4 \$$ of pork meat and $6.42 \$$ of other costs. 
Data have been provided by the company and refer to a full complete and representative production year (2018) in order to avoid seasonal effects and to incorporate the most recent process data prior to the analysis (2019). To avoid odd data and non-representative data outliers, values are calculated as annual averages taking 2018's totals and dividing by the number of functional units or final pork meat kilograms produced in the year.

Figure 1 shows the different inputs and outputs per phase for the selected reference product that come from the pork meat input. Production wastes are minimum since they are mostly reused for other lower value by-products. In the analysis, higher wastes imply higher input costs of raw materials, thus, increasing the social impacts of the production of one functional unit.

So, $3.69 \mathrm{~kg}$ of raw materials are required to produce $3.04 \mathrm{~kg}$ of animal food, needed to produce $1.24 \mathrm{~kg}$ of pork meat. On the other hand, $1.4 \mathrm{~kg}$ of pork meat is the amount necessary to produce $1 \mathrm{~kg}$ of curated pork loin. The final estimated cost of $1 \mathrm{~kg}$ of product is $10.4 \$$.

\section{2. $S-L C A$}

The S-LCA approach is disaggregated by subcategories, which are socially relevant topics or aspects. These subcategories are classified by stakeholder categories. Stakeholder category can be defined as a group of agents, which foreseeably have common interests in accordance with their relationship with the product system under study [21]. In addition, each subcategory contains several different indicators. It has to be highlighted that, unlike environmental and economic approaches, S-LCA relies on indicators that may be: (i) quantitative, (ii) semi-quantitative, and (iii) qualitative. The social categories and indicators are based on the "Guidelines for Social Life Cycle Assessment of Products" and "The Methodological Sheets Guidelines for Subcategories in Social Life Cycle Assessment" [28], designed for the social life cycle assessment of products and services. They include five stakeholders typologies, 23 social and socio-economic subcategories (topics), and 35 different impact categories (indicators).

Related to available databases, there are not many complete sources about social aspects of products and services that include most of the UNEP/SETAC categories and indicators. This approach is broadly used by S-LCA practitioners recently [29]. Several requirements are elicited in the search of the most suitable social impact database. From a list of available databases, the best positioned in the market is PSILCA [27]. PSILCA stands for "Product Social Impact Life Cycle Assessment" and it is a database developed by Green Delta. In order to provide insights into global supply chains, PSILCA uses a multi-regional input/output database called Eora. Eora covers the entire world economy, on an industrial sector basis, comprising 189 countries and nearly 16,000 activity sectors distributed in industries and commodities per country. Eora features raw data drawn from the UN's System of National Accounts, Eurostat, Comtrade database, and many national agencies. The reference year of the database is 2011. As an input-output database, Eora uses money flows to link processes. All process inputs are given in 2011's US dollars, while impact outputs are calculated in equivalent medium risk working hours for 35 impact categories.

ISO 14040:2006 and ISO 14044:2006 are the basis for the social impact assessment. This assessment is made in a similar way to the environmental life cycle assessment, considering also the same initial stages for the analysis design and configuration, as for example, the scope and functional unit. In addition, the impact evaluation for a S-LCA consists in the aggregation of all social impacts weighed by the national and sectoral risk factors, and it is provided in comparable medium risk hours.

In order to evaluate the social impact categories (indicators) with a high relevance for the activities within the value chain of the meat supply chain reference product selected, as well as the influence of these matters on other stakeholders' perceptions of the product (workers, consumers, local community, society and value chain actors), the following steps are considered. 


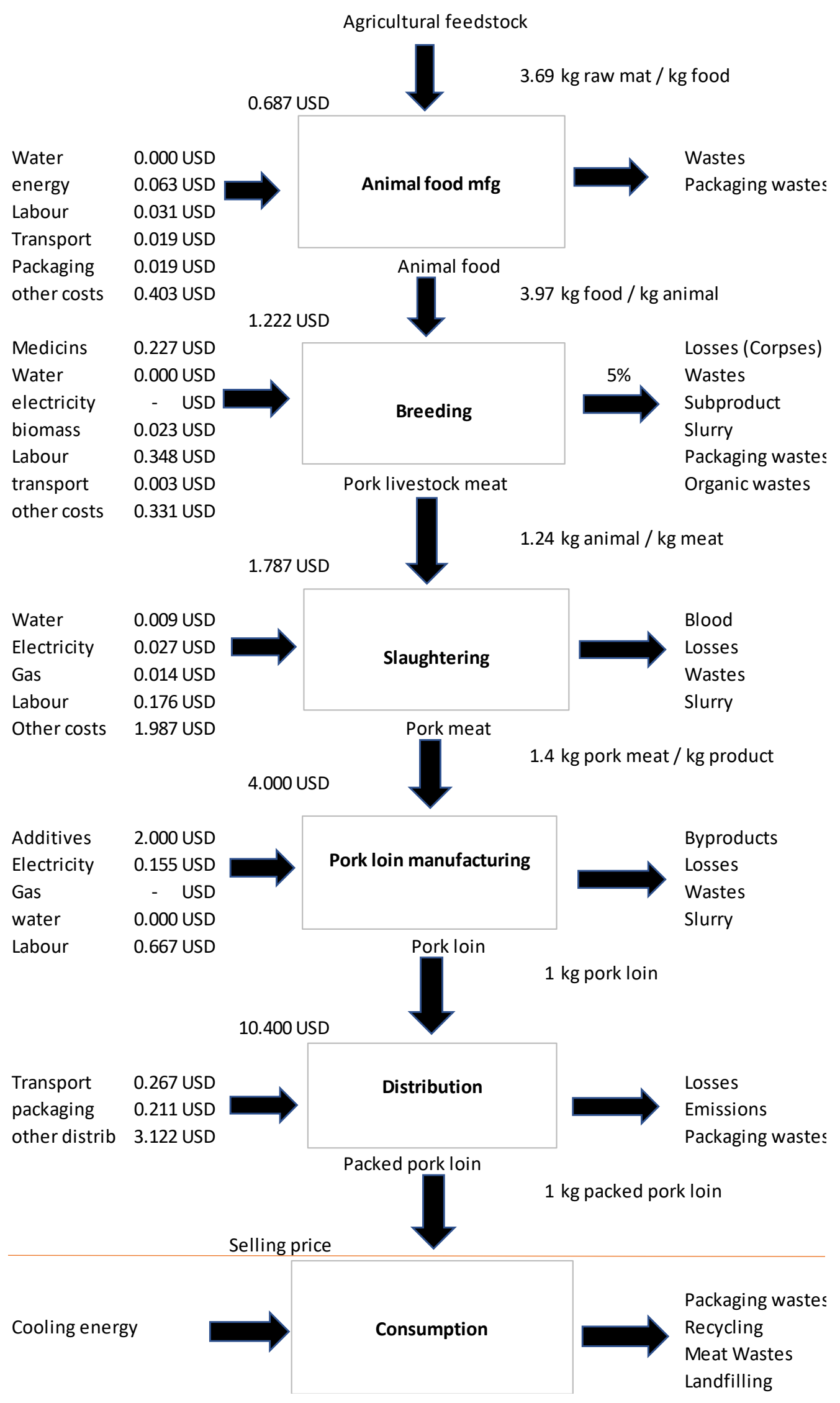

Figure 1. Process flowchart and S-LCA input/output chart in 2011 \$. 


\subsubsection{Pre-Selection}

From the initial set of subcategories, the most meaningful ones, considering the sector under study, are identified according to the following criteria:

1. Geographical relevance: Applicability of the social subcategory within the European context for foreground processes carried out by the case study. To verify this criteria, national-, sector-, and company-specific data and comments for each subcategory in all five stakeholder categories were consulted to industrial peers. National level subcategories, such as child labour or forced labour, are considered as out of boundary in respect of the socioeconomic framework of the EU and, hence, classified as "not applicable".

2. Data availability: Information about the resulting subcategories and indicators from the previous step are then collected from the case study. The idea is to verify if enough data is available for each of the indicators in all the subcategories so they can be successfully included in the assessment, allowing the methodology and the results' structure being equivalent for all parts involved.

3. Bibliography validation: The last criterion verifies the pertinence given by S-LCA specialised literature over the last decade. Three main sources are consulted: (i) the findings from one of the most cited papers in the field, which include the review of 11 S-LCA studies until 2008 [30], (ii) an updated review that comprises an extra 12 S-LCA papers [31], and (iii) the most recent report on S-LCA done by the Joint Research Centre (JRC) in 2018 [32]. The three sources sum a total of 24 researches that serve to identify the most relevant social indicators by their frequency of use.

Following this triple criterion, the pre-selection results is the identification of 10 subcategories: fair salary, working time, discrimination, health and safety, workers' rights, fair competition, contribution to economic development, access to material resources, safe and healthy living conditions, and local employment.

\subsubsection{Impact Assessment}

Based on the social categories and indicators of the pre-selection approach, and the presented Life Cycle Inventory (LCI) of input/output of materials and costs per process (including calculation of the process inputs in 2011 \$ in order to refer to PSILCA database), the social life cycle assessment of the reference product follows the steps below:

1. Specific social data collection from the company for the calculation of the indicators as described in the PSILCA handbook [27]. This also includes the labour cost and time of work to feed the next step.

2. Calculation of the worker hours of the main activity in hours per $\$$ of output. This is calculated as a ratio of the unit labour costs $(\$ / h)$ and the mean hourly wage per employee, as presented below:

$$
\text { Worker hours }=\frac{\text { Unit labour costs }}{\text { Mean hourly labour cost (per employee })}
$$

where:

$$
\begin{aligned}
& \text { Unit labour costs } \\
& =\frac{\text { Compensation of employees (in USD per country-specific sector and year) }}{\text { Gross output (in USD per country-sector and year) }}
\end{aligned}
$$

3. Construction of the simulation models on SimaPRO, using self-made processes supported by the built-in industries and commodities available per country and sector included in PSILCA.

4. Update the risk level per indicator: for each process per country, PSILCA already counts with a level of risk per indicator-from very high risk to very low risk, including a "no risk" level. Although the level of risk is later used as weighting factors during the assessment, this value can be modified based on updated information 
from country and sector statistics, or from primary information from case studies. For example, in the case of minimum wage indicator, the risk is defined as comparison to the living wage of the country ( $y$ value), by calculating the ratio of living wage to minimum wage ( $x$ value) as shown in Table 1. The recalculation of such risks might be considered a preliminary result, given that it allows a first comparison between the case study and the default process in the database.

Table 1. Risk assessment for minimum wage according to PSILCA.

\begin{tabular}{cccc}
\hline Indicator Value $\mathbf{y}$, USD & Logical Connection & Indicator Value $\mathbf{x}$, Ratio & Risk Level \\
\hline $\mathrm{y}>300$ & and & $\mathrm{x}<0.5$ & Very low risk \\
$\mathrm{y} \leq 300$ & and & $\mathrm{x}<0.5$ & \\
$\mathrm{y}>300$ & and & $0.5 \leq \mathrm{x}<0.9$ & Low risk \\
$\mathrm{y} \leq 300$ & and & $0.5 \leq \mathrm{x}<0.9$ & \\
$\mathrm{y}>300$ & and & $0.9 \leq \mathrm{x}<1.3$ & Medium risk \\
$\mathrm{y} \leq 300$ & and & $0.9 \leq \mathrm{x}<1.3$ & \\
$\mathrm{y}>300$ & and & $1.3 \leq \mathrm{x}<1.8$ & High risk \\
$\mathrm{y} \leq 300$ & and & $1.3 \leq \mathrm{x}<1.8$ & \\
& & $\mathrm{x} \geq 1.8$ & Very high risk \\
- & & - & No data \\
\hline
\end{tabular}

5. Run the model and perform the S-LCA assessment: with the model constructed according to the LCI and social information collected from the case study, the S-LCA is run, and the results are interpreted. If necessary, the model might be adjusted in an iterative process.

\subsubsection{Comparative Analysis}

Results from the assessment are given, per indicator, in a unit called medium risk average hours. These values by themselves are not straightforward to be interpreted unless a comparative analysis is done. This comparative analysis is carried out in two levels: first, among the life cycle stages to identify which are the best or worst performing ones. Second, by performing the same assessment for the built-in process for the same country available in the database, so the variation of the medium risk hours between the country default process and the case study, indicates in which indicators the case study improves or worsens compared with the national average.

\section{Results}

With the results of the Social Life Cycle Impact Assessment and the social risks assessed, a process called "manufacture of meat products ALIA pork loin" is created and calibrated, taking as a basis the PSILCA manufacturing of meat products in Spain. Using the new ratio of cost per hour and dollar of the output calculated, the results are expressed in medium risk average hours (med risk) for every social impact indicator.

In absolute terms, total results for the ALIA's pork loin are indicated in Table 2, where only pre-selected subcategories are included. It is important to remark that, although expressed in medium risk hours, comparisons between indicators should not be made.

Based on the methodology proposed, a comparative analysis with other products and process options was made. Values are higher than those obtained for the company's other products like the pork sausage, due to the higher input value in the manufacturing of pork loin with respect to the sausage (more pork meat and higher quality meat). One kilogram of pork loin has a $9 \%$ to $14 \%$ higher social impact than the same amount of pork sausage, as it uses $7 \%$ more pork meat, and the quality of this meat is different. The quality factor is reflected in the higher cost inputs of the pork loin with respect to the sausage.

In terms of life cycle stage contribution, around $62 \%$ of the social impacts come from the product manufacturing, whereas farming and raw materials for animal food elaboration contribute with $19 \%$ and $14 \%$ each. A detailed split of impacts per category can be seen in Figure 2. 
Table 2. ALIA's pork loin S-LCA absolute results per impact indicator and life cycle stage, in medium risk $\$ / \mathrm{h}$.

\begin{tabular}{|c|c|c|c|c|}
\hline Stakeholder & Subcategory & Indicator & Unit & Total \\
\hline \multirow{10}{*}{ Workers } & Discrimination & Gender wage gap & GW med risk & 0.380 \\
\hline & Fair salary & Fair salary & FS med risk & 0.527 \\
\hline & \multirow{5}{*}{ Health and Safety } & DALYs indoor/outdoor air and water pollution & DALY med risk & 0.049 \\
\hline & & Fatal accidents & FA med risk & 0.051 \\
\hline & & Non-fatal accidents & NFA med risk & 0.658 \\
\hline & & Safety measures & SM med risk & 0.454 \\
\hline & & Workers affected by natural disasters & ND med risk & 0.053 \\
\hline & \multirow{2}{*}{ Workers' rights } & Association and bargaining rights & ACB med risk & 0.049 \\
\hline & & Trade unionism & TU med risk & 0.842 \\
\hline & Working time & Weekly hours of work per employee & WH med risk & 0.154 \\
\hline Value Chain Actors & Fair competition & Anti-competitive behaviour & AC med risk & 0.087 \\
\hline \multirow{3}{*}{ Society } & \multirow{3}{*}{$\begin{array}{l}\text { Contribution to } \\
\text { economic development }\end{array}$} & Education & E med risk $\mathrm{h}$ & 0.340 \\
\hline & & Illiteracy & I med risk $h$ & 0.314 \\
\hline & & Youth illiteracy & YI med risk & 0.156 \\
\hline \multirow{9}{*}{ Local Community } & \multirow{5}{*}{$\begin{array}{l}\text { Access to } \\
\text { material resources }\end{array}$} & Biomass consumption & $\mathrm{BM}$ med risk & 0.360 \\
\hline & & Certified environmental management system & CMS med risk & 0.423 \\
\hline & & Fossil fuel consumption & FF med risk & 0.051 \\
\hline & & Industrial water depletion & WU med risk & 0.308 \\
\hline & & Mineral consumption & MC med risk & 0.232 \\
\hline & Local employment & Unemployment & $\mathrm{U}$ med risk $\mathrm{h}$ & 0.609 \\
\hline & \multirow{3}{*}{$\begin{array}{l}\text { Safe and healthy } \\
\text { living conditions }\end{array}$} & Drinking water coverage & DW med risk & 0.072 \\
\hline & & Pollution & $\mathrm{P}$ med risk $\mathrm{h}$ & 0.126 \\
\hline & & Sanitation coverage & SC med risk & 0.140 \\
\hline
\end{tabular}

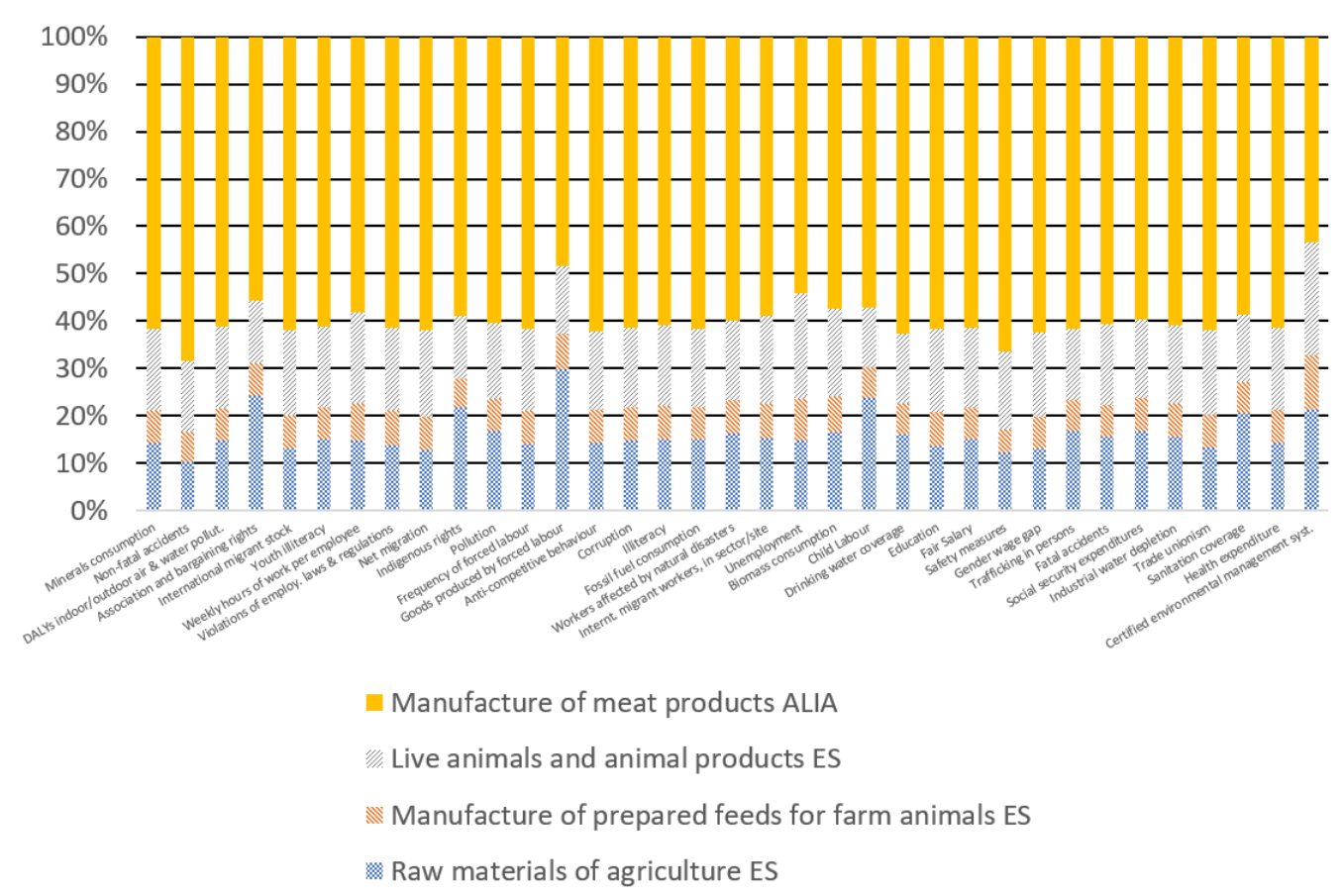

Figure 2. ALIA's pork loin Social LCA relative result per life cycle stage; ES stands for Spain's sector average. 
In the same way, as the second level of comparative analysis, it is possible to compare ALIA's products with a similar-value average meat product produced in Spain, taken from the PSILCA database. This analysis takes $1 \mathrm{~kg}$ of ALIA's pork loin manufacturing process that only considers the manufacturing stage and compares it with a similar amount of other meat product manufactured in Spain. Table 3 shows the Social LCA result comparison between $1 \mathrm{~kg}$ of ALIA's pork loin manufacturing and the manufacturing of the same amount of an average meat product of similar economic value in Spain.

Table 3. Social LCA result comparison between ALIA's pork loin manufacturing and an average meat product manufacturing of similar value in Spain.

\begin{tabular}{|c|c|c|c|c|c|}
\hline Stakeholder & Subcategory & Impact Category & Pork Loin ALIA & Meat Product ES & Comparison \% \\
\hline \multirow{10}{*}{ Workers } & Discrimination & Gender wage gap & 0.237 & 0.355 & $-33 \%$ \\
\hline & Fair salary & Fair salary & 0.324 & 0.429 & $-24 \%$ \\
\hline & \multirow{5}{*}{ Health and Safety } & $\begin{array}{l}\text { DALYs indoor/outdoor } \\
\text { air and water pollution }\end{array}$ & 0.030 & 0.040 & $-25 \%$ \\
\hline & & Fatal accidents & 0.031 & 0.041 & $-25 \%$ \\
\hline & & Non-fatal accidents & 0.450 & 0.620 & $-27 \%$ \\
\hline & & Safety measures & 0.302 & 0.441 & $-32 \%$ \\
\hline & & $\begin{array}{l}\text { Workers affected by } \\
\text { natural disasters }\end{array}$ & 0.032 & 0.042 & $-25 \%$ \\
\hline & \multirow[t]{2}{*}{ Workers' rights } & $\begin{array}{l}\text { Association and } \\
\text { bargaining rights }\end{array}$ & 0.027 & 0.033 & $-17 \%$ \\
\hline & & Trade unionism & 0.521 & 0.704 & $-26 \%$ \\
\hline & Working time & $\begin{array}{l}\text { Weekly hours of work } \\
\text { per employee }\end{array}$ & 0.090 & 0.143 & $-37 \%$ \\
\hline Value Chain Actors & Fair competition & $\begin{array}{l}\text { Anti-competitive } \\
\text { behaviour }\end{array}$ & 0.054 & 0.073 & $-26 \%$ \\
\hline \multirow{3}{*}{ Society } & \multirow{3}{*}{$\begin{array}{l}\text { Contribution to } \\
\text { economic } \\
\text { development }\end{array}$} & Education & 0.209 & 0.283 & $-26 \%$ \\
\hline & & Illiteracy & 0.191 & 0.253 & $-25 \%$ \\
\hline & & Youth illiteracy & 0.096 & 0.127 & $-25 \%$ \\
\hline \multirow{9}{*}{ Local Community } & \multirow{5}{*}{$\begin{array}{l}\text { Access to material } \\
\text { resources }\end{array}$} & Biomass consumption & 0.206 & 0.323 & $-36 \%$ \\
\hline & & $\begin{array}{c}\text { Certified environmental } \\
\text { management system }\end{array}$ & 0.183 & 0.256 & $-28 \%$ \\
\hline & & Fossil fuel consumption & 0.031 & 0.042 & $-25 \%$ \\
\hline & & Industrial water depletion & 0.188 & 0.259 & $-27 \%$ \\
\hline & & Mineral consumption & 0.143 & 0.192 & $-25 \%$ \\
\hline & Local employment & Unemployment & 0.329 & 0.628 & $-48 \%$ \\
\hline & \multirow{3}{*}{$\begin{array}{l}\text { Safe and healthy } \\
\text { living conditions }\end{array}$} & Drinking water coverage & 0.045 & 0.058 & $-22 \%$ \\
\hline & & Pollution & 0.076 & 0.099 & $-23 \%$ \\
\hline & & Sanitation coverage & 0.082 & 0.103 & $-20 \%$ \\
\hline
\end{tabular}

As an average, results of social impacts are $26 \%$ lower for ALIA's products, moving from $-17 \%$ to $-48 \%$ due to the higher productivity of ALIA's process compared to the PSILCA 2011's meat sector average in Spain, and the lower risk assessment in many areas. These comparative results enable to focus on the areas where social performance shows a smaller gap and can be used as a quantitative tool to prioritize actions in the social domain.

The social impact categories where the company is doing well compared to average national values are: 
- Unemployment at national and regional levels: This difference is due to the great improvement in unemployment rates from PSILCA's reference year (2011), exceeding $20 \%$ unemployment rate, to 2018 's rates, still high but below $15 \%$. Unemployment is expected to continue to decrease in the following years, although at a slower pace. However, it remains an area of medium risk.

- Weekly hours per employee: According to the company, ALIAs's workers carry out 40-h working weeks. No extra hours are reported for ALIA's workers.

- Biomass consumption: ALIA's farm uses olive seeds and almond shells as a fuel for winter. However, the mild weather pushes this consumption down to sustainable levels.

- Gender wage gap: Although real and positive (women are worse paid than men), the gap is lower than the sector average (15\% of difference between male and female median wages with respect to men median wage). However, it remains an area of medium risk.

The areas where the social LCA reflects worse results than the sector average are:

- Gender discrimination: number of women in the labour force ( $25 \%$ of the total workforce compared to national standards of 35\% female active population (4T 2018)).

- Association and bargaining rights: Only $10 \%$ of the workforce are members of Worker Unions. The company should encourage higher degrees of Union membership.

- Sanitation coverage: It is very high country-wide, but it does not reach $100 \%$ yet.

\section{Discussion}

Based on the results, in order to identify the most interesting social aspects from the point of view of the company, either for the significance into the business or for the influence on customer's perception of the products, a materiality analysis was done focused to the case study. This step is done to incorporate the perspective of actors involved in the value chain so a more effective focus may be set during the social impact assessment [33]. These value chain actors are the suppliers and facilitators involved during production stages such as production, packaging, transport, commerce, and end-of-life, and do not include consumers as recommended by UNEP/SETAC Life Cycle Initiative. The materiality analysis allows a broader discussion regarding social features significance, expectations, and interest depending on, for example, regions and stakeholder category [34,35]. The prioritization step is done using a scoring system (High-Moderate-Low) for, on one hand, the significance of each of the identified subcategories for the activities within the value chain of the industrial partners' products and, on the other, the influence of these matters on other stakeholders' perceptions of the product.

As mentioned, the materiality matrix is intended to be complete by actors involved in the value chain of the product. This information is collected through semi-structured interviews of managers intended for companies' managers to collect their perspective as sector experts. In the case of the pork loin product, the results are provided according to the feedback received from ALIA given their involvement in most of the value chain stages (from breeding to distribution). Results are shown in Table 4.

Health and safety issues for workers, consumers, and the local community are among the most important subcategories. In the same level of high importance, we can find the subcategory "equal opportunities and discrimination". Following the criteria of the materiality matrix results, the results presented in Table 3 can be summarized in Table 5 in terms of the subcategories with high significance for the business and high influence on stakeholders' perceptions of the product. Therefore, this table is presented to summarize the S-LCA results and to focus the results and conclusions on future research directions.

In general terms, ALIA is performing better in all categories considered. This is due to two reasons: on one side, the more efficient production processes entail a lower input consumption for the same functional unit, thus, reducing the social impacts of all categories. On the other side, the specific working environment for some impact categories reduce the risk and decreases the impact in these categories. The categories where ALIA's production environment is favourable are "average monthly wage", "healthy living conditions", 
"illiteracy", "local employment", and "certified environmental management systems". The categories with higher risk for ALIA are "trade union membership", "safety measures", "contribution to the sector to economic development", "public expenditure on education", women in labour force", "gender wage gap", and "unemployment rate".

Table 4. ALIA's pork loin product materiality matrix.

\begin{tabular}{|c|c|c|c|}
\hline $\begin{array}{l}\text { Stakeholder Related } \\
\text { to Social Topic }\end{array}$ & Subcategory & $\begin{array}{l}\text { Significance for } \\
\text { Your Business }\end{array}$ & $\begin{array}{l}\text { Influence on Stakeholders' } \\
\text { Perceptions of the Product }\end{array}$ \\
\hline \multirow{5}{*}{ Workers } & Fair salary & Moderate & Moderate \\
\hline & Hours of work & Moderate & Moderate \\
\hline & Equal opportunities/Discrimination & High & High \\
\hline & Health and safety & High & High \\
\hline & Freedom of association and collective bargaining & High & Moderate \\
\hline Society & Contribution to economic development & Moderate & High \\
\hline \multirow{3}{*}{ Local Community } & Safe and healthy living conditions & High & High \\
\hline & Access to material resources & Moderate & Moderate \\
\hline & Local employment & Moderate & High \\
\hline \multirow{2}{*}{ Consumers } & End of life responsibility & Moderate & High \\
\hline & Health and safety & High & High \\
\hline \multirow{2}{*}{ Value chain actors } & Fair competition & High & Low \\
\hline & Supplier relationships & Moderate & Low \\
\hline
\end{tabular}

Table 5. Social LCA result comparison between ALIA's pork loin and an average meat product of similar value in Spain. Selected subcategories from the materiality matrix analysis.

\begin{tabular}{|c|c|c|c|c|c|}
\hline Stakeholder & Subcategory & Impact Category & Pork loin ALIA & Meat Product ES & Comparison $\%$ \\
\hline \multirow{6}{*}{ Workers } & Discrimination & Gender wage gap & 0.237 & 0.355 & $-33 \%$ \\
\hline & \multirow{5}{*}{ Health and Safety } & $\begin{array}{l}\text { DALYs indoor/outdoor } \\
\text { air and water pollution }\end{array}$ & 0.030 & 0.040 & $-25 \%$ \\
\hline & & Fatal accidents & 0.031 & 0.041 & $-25 \%$ \\
\hline & & Non-fatal accidents & 0.450 & 0.620 & $-27 \%$ \\
\hline & & Safety measures & 0.302 & 0.441 & $-32 \%$ \\
\hline & & $\begin{array}{l}\text { Workers affected by } \\
\text { natural disasters }\end{array}$ & 0.032 & 0.042 & $-25 \%$ \\
\hline \multirow{3}{*}{ Local Community } & \multirow{3}{*}{$\begin{array}{l}\text { Safe and healthy } \\
\text { living conditions }\end{array}$} & Drinking water coverage & 0.045 & 0.058 & $-22 \%$ \\
\hline & & Pollution & 0.076 & 0.099 & $-23 \%$ \\
\hline & & Sanitation coverage & 0.082 & 0.103 & $-20 \%$ \\
\hline
\end{tabular}

Comparative results with the national meat sector average reveals a shorter gap in "safe and healthy conditions", which is out of reach of the company's social policies to a great extent. It should be noted that comparative analysis may hide interesting conclusions, depending on the reference taken for comparison. The fact that ALIA performs much better than Spain's meat sector average in categories such as unemployment or gender wage gap may not entail a good performance in these categories, since the country's average in these two areas is really low. However, the utility of the results for ALIA is to detect the strong points and weaknesses in their competitive environment at the national level to strengthen the first and mitigate the latter.

The innovations of this analysis compared with other similar S-LCA analysis found in the literature are various:

- This analysis shows the application of the S-LCA methodology to a product and company instead of a whole sector as it is usually the case in literature $[16,31,36,37]$, or a geographical area or country [23]. The results are directly applicable to the company's social policies. 
- This analysis stands on the usage of a widely accepted set of indicators (SETAP) as opposed to other case studies that create an independent set of new indicators $[38,39]$ making future comparisons difficult.

- The selection of the most relevant social categories is tailored to the company's competitive and sociopolitical environment by the implementation of the materiality matrix approach.

\section{Conclusions}

The most interesting social aspects from the point of view of the company, either for the significance to the business or for the influence on customer's perception of the products, are: worker discrimination, health and safety for workers, consumers and local community.

The product manufacturing process is the one most impacting the life cycle phases considered, with around $62 \%$ of the social impacts. In terms of social impact, the main areas or risks that should be addressed from the side of the company are the number of women in the labour force ( $25 \%$ of the total workforce), the gender wage gap ( $15 \%$ of difference between male and female median wages with respect to men median wage), and the trade union density ( $10 \%$ of workforce are members of worker unions).

The comparison with similar value meat products produced in Spain show around a 30\% lower impact in favour of ALIA's products in most of the impact categories under analysis. A higher productivity and risk assessment reduction would contribute to a lower social impact of the products. As for the life cycle stage contribution, around $62 \%$ of the impact comes from the pork loin product manufacturing, whereas for farming it is around $19 \%$ and for agricultural raw materials it is around $14 \%$.

It should be mentioned that the presented results are shown on a static assessment basis. This means that the assessment is based on a reference product and production year. Therefore, a monitoring assessment, as a decision making tool for improvement actions related to the introduction of circular economy innovations in the sector, is recommended for a periodical assessment of the identified subcategories.

The results obtained in comparative terms prove the utility and value added for the company to quantify and understand how well the company is performing in social performance, enabling the identification of strong and weak points, and the prioritization of actions towards achieving more socially responsible products and processes.

Future research opportunities in this field should point in the direction of using the characterized process and product to innovate Corporate Social Responsibility policies with a living lab approach. Social improvement actions should be designed to target specific indicators. Continuous regular assessments made with the presented methodology would reveal the progress made with respect to the costs involved, deriving conclusions on the social cost-benefit domain. The systematic use of the S-LCA methodology for a company's products and services represents a novel and powerful tool adding a social perspective to the sustainable development of companies and entities and, therefore, to the whole society.

Author Contributions: Conceptualization, J.A. and D.Z.-V.; methodology, F.D.-B.; writing-review and editing, F.C. All authors have read and agreed to the published version of the manuscript.

Funding: This contribution has been developed in the framework of the CIRC4LIFE project 'A circular economy approach for lifecycles of products and services', funded by the European Union under the H2020 Innovation Framework Programme, project number 776503.

Institutional Review Board Statement: Not applicable.

Informed Consent Statement: Not applicable.

Data Availability Statement: Not applicable.

Acknowledgments: Authors are very grateful to ALIA for the actual data that allow applying S-LCA methodology to the complete value chain.

Conflicts of Interest: The authors declare no conflict of interest. 


\section{References}

1. Cadena, E.; Rocca, F.; Gutierrez, J.A.; Carvalho, A. Social life cycle assessment methodology for evaluating production process design: Biorefinery case study. J. Clean. Prod. 2019, 238, 117718. [CrossRef]

2. ISO. ISO 14040: Environmental Management_Life Cycle Assessment_Principles and Framework 2006; The International Organization for Standardization: Geneva, Switzerland, 2006.

3. ISO. ISO 14044: Environmental Management_Life Cycle Assessment_Requirements and Guidelines; The International Organization for Standardization: Geneva, Switzerland, 2006.

4. Grubert, E. Rigor in social life cycle assessment: Improving the scientific grounding of SLCA. Int. J. Life Cycle Assess. 2018, 23, 481-491. [CrossRef]

5. Rafiaani, P.; Kuppens, T.; Van Dael, M.; Azadi, H.; Lebailly, P.; Van Passel, S. Social sustainability assessments in the biobased economy: Towards a systemic approach. Renew. Sustain. Energy Rev. 2018, 82, 1839-1853. [CrossRef]

6. Erdman, C.; Mitchum, T.J. Acquisition Research Program Sponsored Report Series. 2014. Available online: https://citeseerx.ist. psu.edu/viewdoc/download?doi=10.1.1.886.7795\&rep=rep1\&type=pdf (accessed on 1 October 2021).

7. Navarro, I.; Yepes, V.; Martí, J.V. Social life cycle assessment of concrete bridge decks exposed to aggressive environments. Environ. Impact Assess. Rev. 2018, 72, 50-63. [CrossRef]

8. European Commission. Communication from the Commission to the European Parliament, the Council, the European Economic and Social Committee and the Committee of the Regions. A Farm to Fork Strategy for a Fair, Healthy and Environmentally-Friendly Food System; European Commission: Brussels, Belgium, 2020.

9. European Food Safety Authority. Special Eurobarometer Wave EB91.3: Food Safety in the EU; European Food Safety Authority: Parma, Italy, 2019.

10. Anafric. Short-Term Outlook. Summer 2021; Anafric: Barcelona, Spain, 2021.

11. Hor, R.; Ly, P.; Putra, A.; Ishizaki, R.; Ahamed, T.; Noguchi, R. Estimation of Carbon Dioxide Emissions from a Traditional Nutrient-Rich Cambodian Diet Food Production System Using Life Cycle Assessment. Sustainability 2021, 13, 3660. [CrossRef]

12. Wilfart, A.; Gac, A.; Salaün, Y.; Aubin, J.; Espagnol, S. Allocation in the LCA of meat products: Is agreement possible? Clean. Environ. Syst. 2021, 2, 100028. [CrossRef]

13. Chen, W.; Holden, N.M. Social life cycle assessment of average Irish dairy farm. Int. J. Life Cycle Assess. 2017, $22,1459-1472$. [CrossRef]

14. Lafontaine, M.; Couture, J.M. Environmental and Socioeconomic Life Cycle Assessment of Canadian Milk; Quantis Canada: Montreal, QC, Canada; AGECO: Quebec, QC, Canada; CIRAIG: Montreal, QC, Canada, 2012.

15. Paragahawewa, U.; Blankett, P.; Smal, B.L. Social Life Cycle Analysis (S-LCA): Some Methodological Issues and Potential Application to Cheese Production in New Zealand; AgResearch Ltd.: Lincoln, New Zealand, 2009.

16. Zira, S.; Röös, E.; Ivarsson, E.; Hoffmann, R.; Rydhmer, L. Social life cycle assessment of Swedish organic and conventional pork production. Int. J. Life Cycle Assess. 2020, 25, 1957-1975. [CrossRef]

17. Valente, C.; Moller, H.; Johnsen, F.M.; Saxegard, S.; Brunsdon, E.R.; Alvseike, O.A. Life Cycle Sustainability assessment of a novel slaughter concept. J. of Clean. Product. 2020, 272, 122651. [CrossRef]

18. Florman, M.; Klingler-Vidra, R.; Facada, M.J. A Critical Evaluation of Social Impact Assessment Methodologies and a Call to Measure Economic and Social Impact Holistically through the External Rate of Return Platform; Working Paper No. \#1602; LSE Enterprise: London, UK, 2016; pp. 1-32.

19. Esteves, A.M.; Franks, D.; Vanclay, F. Social impact assessment: The state of the art. Impact Assess. Proj. Apprais. 2012, 30, 34-42. [CrossRef]

20. Norris, B.C.; Traverso, M.; Neugebauer, S.; Ekener, E.; Schaubroeck, T.; Garrido, R.S.; Berger, M.; Valdivia, S.; Lehmann, A.; Finkbeiner, M.; et al. Guidelines for Social Life Cycle Assessment of Products and Organizations; United Nations Environment Programme: Nairobi, Kenya, 2020.

21. Fontes, J.; Bolhuis, A.; Bogaers, K.; Saling, P.; van Gelder, R.; Traverso, M.; Das Gupta, J.; Bosch, H.; Morris, D.; Woodyard, D.; et al. Handbook for Product Social Impact Assessment; PRé Sustainability: Amersfoot, The Netherlands, 2015.

22. Rainock, M.; Everett, D.; Pack, A.; Dahlin, E.C.; Mattson, C.A. The social impacts of products: A review. Impact Assess. Proj. Apprais. 2018, 36, 230-241. [CrossRef]

23. Venkatesh, G. Critique of selected peer-reviewed publications on applied social life cycle assessment: Focus on cases from developing countries. Clean Technol. Environ. Policy 2019, 21, 413-430. [CrossRef]

24. Rivera-Huerta, A.; Lozano, M.D.L.S.R.; Padilla-Rivera, A.; Güereca, L.P. Social Sustainability Assessment in Livestock Production: A Social Life Cycle Assessment Approach. Sustainability 2019, 11, 4419. [CrossRef]

25. Su, D.; Peng, W. Eco-accounting infrastructure. In Concurrent Engineering Approaches for Sustainable Product Development in a Multi-Disciplinary Environment; Springer: New York, NY, USA, 2020; pp. 73-84.

26. CIRC4LIFE. Report on the Development of Ecopoints Methods; European Commission: Brussels, Belgium, 2020.

27. GreenDelta. PSILCA-A Product Social Impact Life Cycle Assessment Database; Database Version 1.0. Documentation; GreenDelta: Berlin, Germany, 2016.

28. Benoît, C.; Traverso, M.; Valdivia, S.; Vickery-Niederman, G.; Franze, J.; Azuero, L.; Ciroth, A.; Mazijn, B.; Aulisio, D. The Methodological Sheets for Subcategories in Social Life Cycle Assessment (S-LCA); UNEP: Nairobi, Kenya; SETAC: Brussels, Belgium, 2013. 
29. Petti, L.; Serreli, M.; Di Cesare, S. Systematic literature review in social life cycle assessment. Int. J. Life Cycle Assess. 2018, 23, 422-431. [CrossRef]

30. Jørgensen, A.; Le Bocq, A.; Nazarkina, L.; Hauschild, M. Methodologies for social life cycle assessment. Int. J. Life Cycle Assess. 2008, 13, 96-103. [CrossRef]

31. Siebert, A.; Bezama, A.; O'Keeffe, S.; Thrän, D. Social life cycle assessment indices and indicators to monitor the social implications of wood-based products. J. Clean. Prod. 2018, 172, 4074-4084. [CrossRef]

32. Mancini, L. Social Assessment of Raw Materials Supply Chains; European Comission: Brussels, Belgium, 2018.

33. Bellantuono, N.; Pontrandolfo, P.; Scozzi, B. Capturing the Stakeholders' View in Sustainability Reporting: A Novel Approach. Sustainability 2016, 8, 379. [CrossRef]

34. GRI. G4 Sustainability Reporting Guidelines_Part 1: Reporting Principles and Standard Disclosures; GRI: Amsterdam, The Netherlands, 2013.

35. PRé Sustainability; Members of the Roundtable for Product Social Metrics. Handbook for Product Social Impact Assessment_-Roundtable for Product Social Metrics; PRé Sustainability: LE Amersfoort, The Netherlands, 2020.

36. Karlewski, H.; Lehmann, A.; Ruhland, K.; Finkbeiner, M. A Practical Approach for Social Life Cycle Assessment in the Automotive Industry. Resources 2019, 8, 146. [CrossRef]

37. Martucci, O.; Arcese, G.; Montauti, C.; Acampora, A. Social Aspects in the Wine Sector: Comparison between Social Life Cycle Assessment and VIVA Sustainable Wine Project Indicators. Resources 2019, 8, 69. [CrossRef]

38. Reinales, D.; Zambrana-Vasquez, D.; Saez-De-Guinoa, A. Social Life Cycle Assessment of Product Value Chains Under a Circular Economy Approach: A Case Study in the Plastic Packaging Sector. Sustainability 2020, 12, 6671. [CrossRef]

39. Blaauw, S.A.; Maina, J.W.; Grobler, L.J. Social Life Cycle Inventory for Pavements-A Case Study of South Africa. Transp. Eng. 2021, 4, 100060. [CrossRef] 